\title{
REMAT: Análise do Perfil de seus Usuários por meio da Ferramenta Google Analytics e Difusão do Conhecimento Científico entre Professores e Estudantes de Matemática
}

\author{
Carollayne Cesar Vissirini \\ Instituto Federal de Educação, Ciência e Tecnologia do Rio Grande do Sul (IFRS) \\ carollayne.vissirini@caxias.ifrs.edu.br \\ Rafael Eduardo da Silva \\ Instituto Federal de Educação, Ciência e Tecnologia do Rio Grande do Sul (IFRS) \\ rafael.dasilva@caxias.ifrs.edu.br \\ Greice da Silva Lorenzzetti Andreis \\ Instituto Federal de Educação, Ciência e Tecnologia do Rio Grande do Sul (IFRS) \\ greice.andreis@caxias.ifrs.edu.br \\ Katia Arcaro \\ Instituto Federal de Educação, Ciência e Tecnologia do Rio Grande do Sul (IFRS) \\ katia.arcaro@,caxias.ifrs.edu.br
}

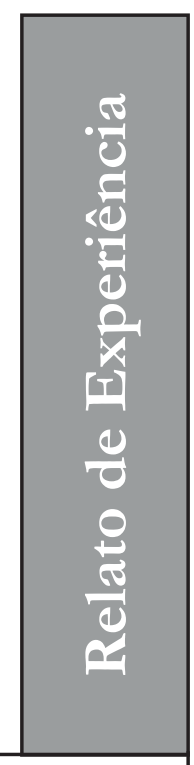

\section{Resumo}

A REMAT: Revista Eletrônica da Matemática (e-ISSN 2447-2689) vem se constituindo enquanto periódico científico desde 2015, tendo como missão compartilhar práticas educativas e resultados de pesquisas que se relacionem com a Matemática. Na busca pelo aperfeiçoamento, evoluções ocorreram em seus processos e fluxos e questões como a acessibilidade digital foram tratadas, bem como investiu-se na divulgação do periódico por meio de correio eletrônico, site institucional e redes sociais. Visando fomentar a busca pelo conhecimento científico e caracterizar o público leitor da REMAT, a revista aderiu ao Google Analytics, um software on-line de análise de acessos que é disponibilizado gratuitamente pela Google. A diversidade e a natureza dos dados já coletados, embora muito recentes ainda, mostram potencial não só para o mapeamento do perfil dos leitores, mas também de suas necessidades e preferências, bem como fazer um acompanhamento das mudanças desse perfil com a evolução da revista. A coleta e análise dessas informações permitirá entregar ao público-alvo cada vez mais qualidade de conteúdo e facilidade de acesso. Além disso, uma pesquisa por formulário eletrônico foi realizada e buscou verificar se professores de Matemática de diferentes níveis de ensino e acadêmicos do curso de Licenciatura em Matemática utilizam artigos científicos para enriquecer o planejamento de suas aulas. Como principal resultado obteve-se que $50 \%$ dos entrevistados já aplicaram conhecimentos obtidos a partir da leitura de artigos científicos no planejamento de aulas de Matemática.

Palavras-Chave

Perfil do Usuário. Google Analytics. Artigos Científicos. Fomento ao Conhecimento Científico.

\section{INTRODUÇÃO}

A Revista Eletrônica da Matemática (REMAT) (e-ISSN 2447-2689) teve como idealizadores um grupo de docentes do Instituto Federal de Educação, Ciência e Tecnologia do Rio Grande do Sul (IFRS), Campus Caxias do Sul, e como missão compartilhar práticas educativas e resultados de pesquisas que se relacionam com a Matemática (ANDREIS et al, 2016).

Ao longo desses quase quatro anos de existência, evoluções ocorreram em seus processos, fluxos e composição da equipe 
editorial. Questões como a acessibilidade digital foram tratadas (ANDREIS et al, 2017; SILVA et al, 2018a) e a divulgação do periódico foi intensificada por meio de correio eletrônico, site institucional e redes sociais. Resultado desse esforço conjunto tem sido as submissões com maior qualidade de escrita e de temas. A divulgação nas redes sociais tem sido feita por meio de banner (Figura 1), divulgando periodicamente um dos artigos já publicados na REMAT, com a finalidade de dar maior visibilidade aos nossos autores e suas pesquisas.

Figura 1 - Banner de divulgação de artigo publicado na REMAT para o Facebook

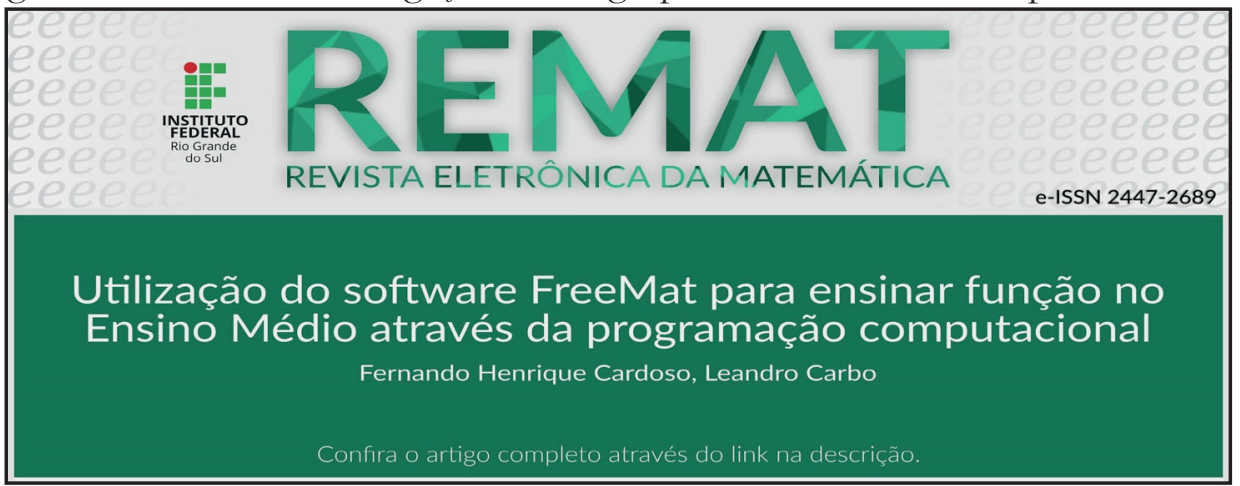

Fonte: Material da REMAT (2017)

Com esse tempo de caminhada, no ano de 2018 a Equipe Editorial questionouse sobre qual o espaço que a REMAT vem ocupando em meio aos periódicos científicos, qual sua contribuição e quem são seus leitores. As primeiras análises dessa busca são compartilhadas no presente artigo. É realizada uma análise do perfil dos leitores da REMAT com dados coletados com o Google Analytics no ano de 2018. Também, são mostrados os resultados de uma pesquisa realizada com professores de Matemática e estudantes de Licenciatura em Matemática sobre a utilização de periódicos científicos, incluindo o incentivo à utilização do conhecimento produzido por meio de artigos científicos. Tais iniciativas visam caracterizar o público leitor da REMAT, promover melhorias no periódico e fomentar a busca pelo conhecimento científico.

\section{IMPLANTAÇÃO DA FERRAMENTA GOOGLE ANALYTICS NA REMAT}

O constante crescimento do uso de revistas eletrônicas demanda que os administradores de portais nos quais as revistas eletrônicas estão hospedadas tenham indicadores sobre o perfil dos usuários que acessam determinada revista. O uso de periódicos científicos em formato eletrônico é uma rotina nos atuais hábitos dos pesquisadores, principalmente pela diversidade de títulos com acesso aberto, um dos requisitos primordiais para a visibilidade e acessibilidade da publicação (PACKER; MENEGHINI, 2006). Para tanto, dispõe-se de diversos plugins e softwares de monitoramento de acessos, entre eles, o Google Analytics que foi implantado recentemente na REMAT.

O Google Analytics é um software online e disponibilizado gratuitamente pela empresa Google. O sistema foi modelado com base no sistema de estatísticas Urchin, da Urchin Software Corporation, adquirida pela Google em abril de 2005. É bastante utilizado por webmasters e profissionais da área de Marketing para a otimização de sites e portais para campanhas de marketing, mas suas diversas ferramentas de análises permitem que os portais de periódicos façam uso desse software.

A implantação da ferramenta para a análise de um portal necessita, assim como 
todos os serviços da Google, que se tenha uma conta de usuário. Ao acessar a interface do Google Analytics pode-se criar subcontas para análises de diversos sites. Cada site monitorado recebe um código alfanumérico de acompanhamento que segue o formato UA-XXXXX-XX. A implementação do Google Analytics com o site se dá pela linguagem de programação JavaScript. Buscando facilitar essa implementação, o sistema Analytics disponibiliza uma implantação standard, na qual o usuário que está configurando o serviço copia o código na interface Analytics e cola no site e/ou portal que deseja fazer a coleta dos dados. Esse script é responsável por fazer a aquisição das interações no site analisado. Essas interações recebem um nome de HITS. Um HIT é um delimitador do Google Analytics, e é por meio dele que a interface define os limites de coleta dos dados.

Implantado na REMAT em 04 de junho de 2018, foram analisadas as seguintes métricas no período de 04 de junho a 20 de dezembro de 2018: número de usuários em interação, tempo de acesso por usuário, número de páginas visualizadas, tipo de dispositivo com o qual o usuário acessa o site, localização geográfica dos acessos e forma como o usuário chega ao site da revista.

$\mathrm{Na}$ Figura 2 apresenta-se a métrica "Usuários". Essa métrica mostra quantos usuários interagiram com o site. Entende-se interação por total de dispositivos (browsers) que acessaram o site.

Figura 2 - Número de usuários que interagiram com o site de 04/06/2018 a 20/12/2018

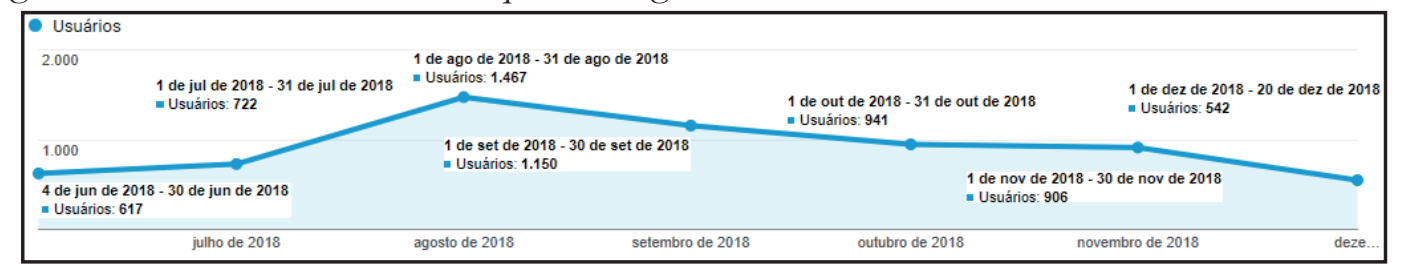

Fonte: Relatório Google Analytics (2018)

$\mathrm{Na}$ Figura 3 mostra-se a métrica "Sessões". Essa métrica refere-se ao período de tempo durante o qual cada usuário interage com o site. Cada sessão tem por padrão a duração de 30 minutos. Todos os dados de utilização e interação são associados em uma sessão.

Figura 3 - Número de sessões visitadas de 04/06/2018 a 20/12/2018

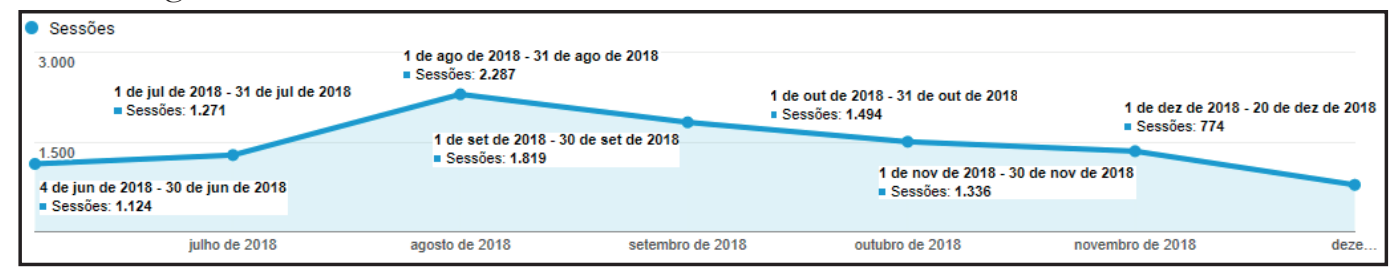

Fonte: Relatório Google Analytics (2018)

A Figura 4 apresenta a métrica "Visualizações de página". Esta métrica trata do número total de páginas visualizadas.
São contabilizadas também as visualizações repetidas de uma única página. 
Figura 4 - Número de visualizações de página de 04/06/2018 a 20/12/2018

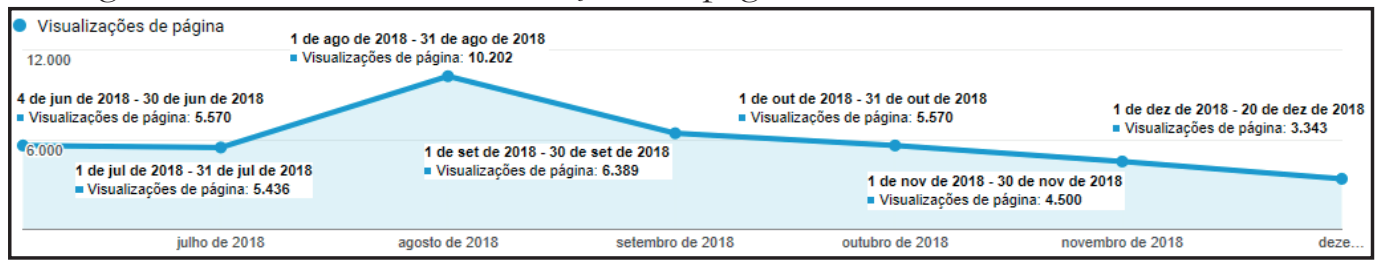

Fonte: Relatório Google Analytics (2018)

$\mathrm{Na}$ Figura 5 apresentam-se as sessões para o acesso. consultadas por tipo de dispositivo utilizado

Figura 5 - Tipos de dispositivos utilizados para acesso de 04/06/2018 a 20/12/2018

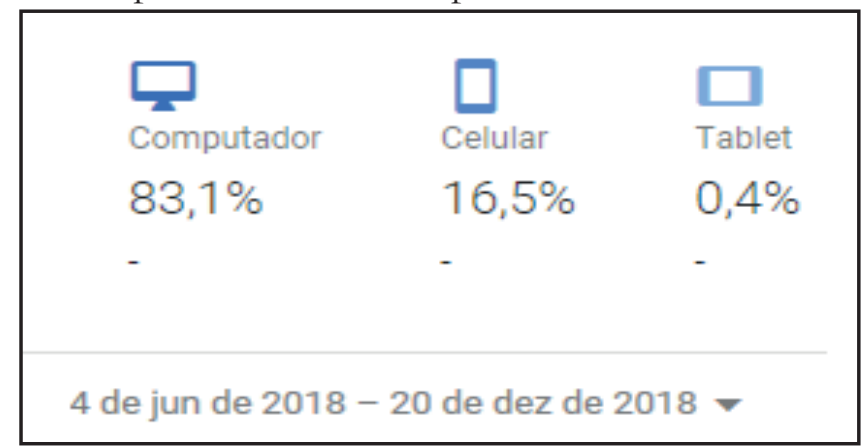

Fonte: Relatório Google Analytics (2018)

$\mathrm{Na}$ Figura 6 apresentam-se os dados geográficos de onde foram feitos os acessos às sessões da REMAT. O Google Analytics permite, nesse campo, filtrar os países por estados e os estados por cidades. Com isso pode-se saber exatamente a localização do acesso de uma determinada sessão.

Figura 6 - Localização geográfica das sessões de 04/06/2018 a 20/12/2018

\begin{tabular}{|c|c|c|}
\hline \multirow[t]{2}{*}{ Pais } & Usuários $\quad \checkmark \downarrow$ & Usuários \\
\hline & $\begin{array}{r}5.586 \\
\text { Porcentagem do total: } 100,00 \% \\
(5.566)\end{array}$ & $\begin{array}{r}5.586 \\
\text { Porcentagem do total: } \\
100,00 \% \text { (5.586) }\end{array}$ \\
\hline 1. $\quad$ Brazil & 5.172 & $92,47 \%$ \\
\hline 2. 四 United States & 161 & $2,88 \%$ \\
\hline 3. $\square$ Portugal & 42 & $0,75 \%$ \\
\hline 4. $=$ Argentina & 24 & $0,43 \%$ \\
\hline 5. $=$ Spain & 22 & $0,39 \%$ \\
\hline 6. $\| \amalg$ Peru & 22 & $0,39 \%$ \\
\hline 7. $\square$ Chile & 18 & $0,32 \%$ \\
\hline 8. $\square$ Colombia & 17 & $0,30 \%$ \\
\hline 9. $\square$ India & 16 & $0,29 \%$ \\
\hline 10. 10 China & 10 & $0,18 \%$ \\
\hline 11. & 10 & $0,18 \%$ \\
\hline 12. $\equiv$ Mozambique & 7 & $0,13 \%$ \\
\hline
\end{tabular}

Fonte: Relatório Google Analytics (2018) 
A Figura 7 traz a métrica "Aquisição", que informa como o usuário chegou até o site. O indicador "direct" contabiliza os acessos feitos diretamente pelo endereço inicial da REMAT (https://periodicos.ifrs.edu.br/index.php/REMAT/ index).

Figura 7 - Origens dos acessos de 04/06/2018 a 20/12/2018

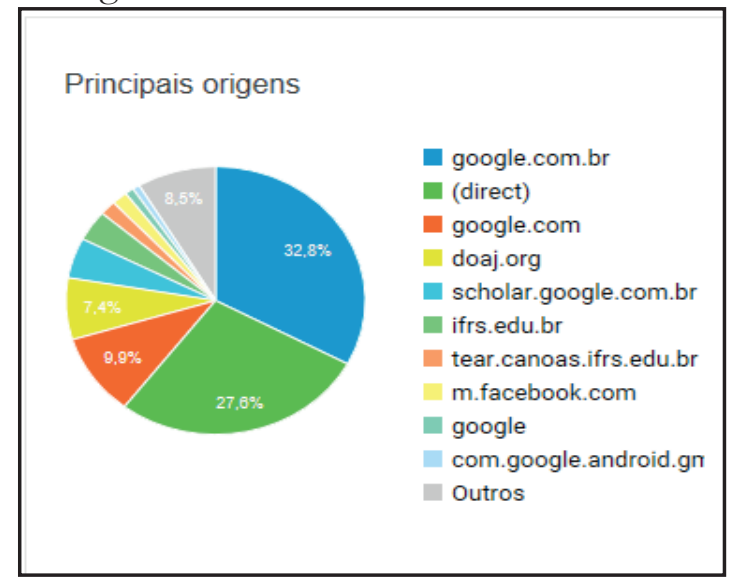

Fonte: Relatório Google Analytics (2018)

Esses parâmetros se mostram importantes na medida que auxiliam a traçar o perfil do público que o periódico está atendendo, bem como fazer um acompanhamento das mudanças desse perfil com a evolução da revista. Apesar de ainda muito recente sua utilização na REMAT, uma rápida análise dos gráficos das Figuras 2 a 4 indica uma média de 906 usuários, 1.443 sessões e 5.858 visualizações de página por mês. A médio prazo, essas informações podem indicar momentos oportunos para divulgações e locais estratégicos para informações a autores e leitores. Além disso, a Figura 5 mostra que $83,1 \%$ dos acessos se deram por meio de computadores, informação que poderá nortear quanto a melhorias que podem ser feitas no acesso em computadores, e também melhorias que podem ser realizadas para uma maior e melhor utilização do site em celulares e tablets.

Uma vez que a REMAT está aberta a publicar em outros idiomas que não somente o português, a localização geográfica dos acessos (Figura 6) pode indicar a magnitude do alcance que a revista está tendo em função da variedade de idiomas em que ocorreram publicações. Além disso, o mapeamento por região ou por cidade também pode auxiliar a traçar o perfil dos usuários e os assuntos que melhor os atende, no sentido de aprimorar a temática da revista e talvez guiar na produção de números extras com temáticas exclusivas.

Por fim, obter informações acerca de como o leitor chegou até o periódico (Figura 7) é um indicativo também da popularidade da marca, visto que o segundo maior acesso foi por vias diretas, sem mecanismos de busca. Não menos importante é conhecer os buscadores nos quais o site já tem visibilidade e quais ainda demandam alguma intervenção para aumentar o alcance das publicações.

\section{FOMENTO À UTILIZAÇÃO DE PERIÓDICOS CIENTÍFICOS POR PROFESSORES E ESTUDANTES DE MATEMÁTICA}

Com o intuito de fomentar a leitura de artigos científicos, assim como divulgar as publicações da REMAT, a professores e estudantes (graduação e pós-graduação) de Matemática, realizou-se uma pesquisa sobre a utilização de artigos científicos por este público.

A pesquisa procurou verificar se professores de Matemática, em diferentes níveis de ensino, bem como acadêmicos de 
cursos de Licenciatura em Matemática utilizam artigos científicos para complementar sua formação e/ou enriquecer o planejamento de suas aulas. A pesquisa foi aplicada por meio de formulário eletrônico disponibilizado no site do IFRS, Campus Caxias do Sul e enviado por correio eletrônico. Com o objetivo de atingir o maior número de professores da área de Matemática, o formulário foi encaminhado para os seguintes grupos:

- Alunos e servidores do IFRS, Campus Caxias do Sul (além de professores de Matemática, o Campus possui o curso de Licenciatura em Matemática);

- Servidores do IFRS (todos os campos do IFRS possuem docentes da área de Matemática, e alguns deles também possuem o curso de Licenciatura em Matemática);

- Usuários da REMAT (em sua maioria docentes de Ensino Superior e PósGraduação; este grupo foi de abrangência internacional);

- Instituições de Ensino Superior do Rio Grande do Sul que possuem cursos na área de Matemática (contatos via coordenadores de curso);

- Sindicato dos Professores de Caxias do Sul;

- Secretaria Municipal da Educação de Caxias do Sul e de Flores da Cunha;

- $4^{a}$ Coordenadoria Regional de Educação - Caxias do Sul.

Para participar da pesquisa, os respondentes primeiramente consentiram por meio de um Termo de Compromisso, tendo sido obtidas 92 respostas autorizadas. As primeiras questões referiram-se ao perfil dos participantes, com relação à sua atuação na docência, ou, em caso de serem estudantes de Matemática, se eram estudantes de Graduação ou de Pós-Graduação. Os resultados encontram-se na Tabela 1.

Tabela 1 - Perfil dos participantes da pesquisa

\begin{tabular}{|l|c|}
\hline Aluno de Licenciatura em Matemática & 20 \\
\hline Aluno de Pós-Graduação em Matemática & 2 \\
\hline Professor de Matemática (Ensino Fundamental) & 5 \\
\hline Professor de Matemática (Ensino Fundamental), Aluno de Licenciatura em Matemática & 2 \\
\hline Professor de Matemática (Ensino Fundamental), Aluno de Pós-Graduação em Matemática & 3 \\
\hline Professor de Matemática (Ensino Fundamental), Professor de Matemática (Ensino Médio) & 7 \\
\hline $\begin{array}{l}\text { Professor de Matemática (Ensino Fundamental), Professor de Matemática (Ensino Médio), Aluno } \\
\text { de Licenciatura em Matemática }\end{array}$ & 1 \\
\hline $\begin{array}{l}\text { Professor de Matemática (Ensino Fundamental), Professor de Matemática (Ensino Médio), Aluno } \\
\text { de Pós-Graduação em Matemática }\end{array}$ & 1 \\
\hline $\begin{array}{l}\text { Professor de Matemática (Ensino Fundamental), Professor de Matemática (Ensino Médio), } \\
\text { Professor de Matemática (Ensino Superior) }\end{array}$ & 2 \\
\hline $\begin{array}{l}\text { Professor de Matemática (Ensino Fundamental), Professor de Matemática (Ensino Médio), } \\
\text { Professor de Matemática (Ensino Superior), Professor de Matemática (Pós-Graduação), Aluno de } \\
\text { Pós-Graduação em Matemática }\end{array}$ & 1 \\
\hline Professor de Matemática (Ensino Médio) & 10 \\
\hline Professor de Matemática (Ensino Médio), Aluno de Licenciatura em Matemática & 1 \\
\hline Professor de Matemática (Ensino Médio), Aluno de Pós-Graduação em Matemática & 1 \\
\hline Professor de Matemática (Ensino Médio), Professor de Matemática (Ensino Superior) & 7 \\
\hline $\begin{array}{l}\text { Professor de Matemática (Ensino Médio), Professor de Matemática (Ensino Superior), Aluno de } \\
\text { Pós-Graduação em Matemática }\end{array}$ & 1 \\
\hline
\end{tabular}


REMAT: análise do perfil de seus usuários por meio da ferramenta Google Analytics e difusão do conhecimento científico entre professores e estudantes de matemática

\begin{tabular}{|l|c|}
\hline $\begin{array}{l}\text { Professor de Matemática (Ensino Médio), Professor de Matemática (Ensino Superior), Professor } \\
\text { de Matemática (Pós-Graduação) }\end{array}$ & 3 \\
\hline Professor de Matemática (Ensino Superior) & 12 \\
\hline Professor de Matemática (Ensino Superior), Aluno de Pós-Graduação em Matemática & 2 \\
\hline Professor de Matemática (Ensino Superior), Professor de Matemática (Pós-Graduação) & 4 \\
\hline Professor de Matemática (Pós-Graduação) & 2 \\
\hline Professor de outras áreas & 2 \\
\hline Técnico-administrativo & 3 \\
\hline
\end{tabular}

Fonte: Dados da pesquisa (2018)

Com a intenção de identificar os periódicos científicos mais lembrados pelo grupo pesquisado, foi realizada a seguinte pergunta no questionário: "Apresentamos a seguir uma lista com os 57 periódicos científicos que receberam classificação na área do Ensino no quadriênio 2013-2016 pelo Qualis Periódicos. Marque aqueles que você costuma acessar, ou já consultou para uma determinada pesquisa ou leitura de interesse." Os dez periódicos mais acessados por este grupo são apresentados na Tabela 2.

Tabela 2 - Periódicos da área da Matemática mais lembrados pelo grupo de entrevistados

\begin{tabular}{|l|c|}
\hline \multicolumn{1}{|c|}{ Periódico } & $\begin{array}{c}\text { Número de vezes que or } \\
\text { periódico foi lembrado na } \\
\text { pesquisa }\end{array}$ \\
\hline REMAT: Revista Eletrônica da Matemática & 49 \\
\hline Revista do Professor da Matemática & 36 \\
\hline BOLEMA: Boletim de Educação Matemática (online) & 35 \\
\hline $\begin{array}{l}\text { Educação e Matemática: Revista da Associação de Professores de } \\
\text { Matemática }\end{array}$ & 18 \\
\hline REVEMAT & 16 \\
\hline ACTA SCIENTIAE: Revista de Ensino de Ciências e Matemática & 16 \\
\hline Educação Matemática em Revista - RS & 16 \\
\hline Biomatemática & 13 \\
\hline Computational \& Applied Mathematics & 12 \\
\hline Educação e Matemática em Foco (UEPB) & 11 \\
\hline
\end{tabular}

Fonte: Dados da pesquisa (2018)

O fato da REMAT aparecer como o periódico mais acessado entre os periódicos listados deve-se à escolha do grupo: 70\% já conhecia o periódico por ser da mesma instituição ou por ser usuário do periódico. Independente desse resultado, o fato importante é que a maior parte dos periódicos citados são conhecidos (apenas 4 dos 57 não foram assinalados), demonstrando que há uma familiaridade com a leitura científica pelo grupo escolhido.

Com relação à docência, questionouse: "Você já elaborou uma aula para o ensino de Matemática que teve por base a leitura de algum artigo científico? Em caso afirmativo, você pode nos contar esta experiência?”. 
Dos entrevistados, 50\% responderam que já utilizaram artigos para a elaboração de aulas.
Destes, 36 relataram algumas experiências de suas práticas (Tabela 3).

Tabela 3 - Relatos dos entrevistados acerca do uso de artigos científicos para a elaboração de aulas de Matemática (foram corrigidos erros ortográficos)

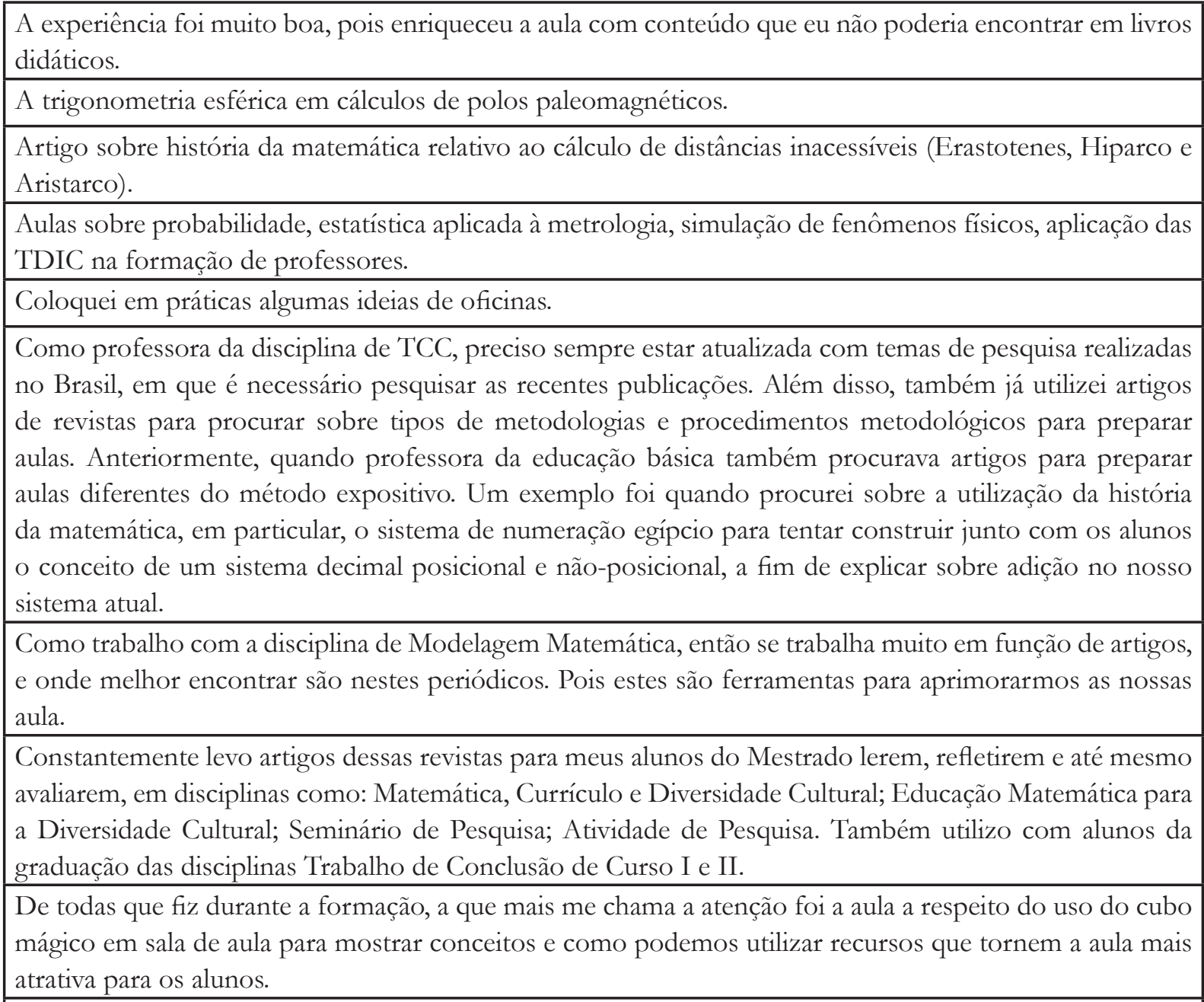

Desenvolver projetos de pesquisa e aplicação da Matemática em sala de aula, os quais resultaram em projetos de ótima qualidade, como por exemplo: O braço tecnológico; Construindo com a Matemática; Alguns do nosso planeta Azul.

Dou aula de apoio em um projeto de extensão.

Durante as aulas sempre é muito importante termos uma base científica, que nos ajude a comprovar algumas teorias apresentadas. A informação, através do acesso a estudos e pesquisas realizadas por nossos colegas.

É maravilhoso, pois estimula alunos com perfil acadêmico a se interessar em elaborar e publicar artigos.

Em determinadas situações os artigos podem gerar debates interessantes e inovadores, e também possibilitam a construção de aulas muito produtivas.

Estava realizando uma pesquisa sobre o empirismo e realizei diversas leituras para construir um plano de ensino para um minicurso de trigonometria para Ensino Médio. Foi interessante verificar que a teoria condiz com a prática. 
REMAT: análise do perfil de seus usuários por meio da ferramenta Google Analytics e difusão do conhecimento científico entre professores e estudantes de matemática

Foi sobre o crescimento populacional (modelos clássicos) e relação com o aumento de resíduos sólidos (diversos tipos de lixo). Os alunos gostaram muito até trocar as garrafas pet por canecas e garrafas de vidro.

Foi uma experiência muito enriquecedora. Tanto que este plano eu adotei como permanente na introdução do conteúdo de equações.

Foi uma ótima experiência, pois os artigos científicos trazem informações exatas e devidamente referenciadas, o que facilita o conhecimento e entendimento dos conteúdos da aula.

Gosto muito de pesquisar os temas de meus trabalhos e planejamento da regência de estágio em artigos, para enriquecer e amplificar conceitos de livros didáticos. Minhas experiências em sala de aula, procuro sempre pesquisar oficinas, atividades experimentais e tecnologias, e estes não se fazem presentes na maioria dos livros didáticos para educação básica na disciplina de matemática.

Já tive a oportunidade de realizar formação docente para professores da Educação Básica da rede municipal e estadual de Vacaria. Nessas atividades me baseio em leituras de artigos e livros em Educação Matemática e Metodologia de Ensino. Ainda não utilizei a leitura de um artigo em particular como atividade na formação docente. Apenas como referência.

Já usei alguns artigos que dão exemplos de jogos relacionados a matemática, confeccionei os jogos e apliquei nas turmas de sexto e sétimo ano do ensino fundamental.

Modelagem matemática na Educação Matemática. Fui uma experiência onde criamos uma função para verificar o consumo de água de uma unidade do Sistema Prisional Brasileiro. Depois de verificado a vazão média de todas as torneiras, criamos uma função para mensurar a quantidade de água que era desperdiçada durante o banho por minuto, a partir do momento que era dado o sinal de inicialização do banho até o momento em que o aluno entrava realmente no banho.

$\mathrm{Na}$ verdade não elaborei uma aula e sim atividades a serem aplicadas em sala de aula junto aos alunos. Muitos artigos trazem experiências realizadas, adaptei algumas destas experiências, especialmente em modelagem matemática para trabalhar em sala de aula.

Nas aulas de educação financeira fiz uma dinâmica de discussão sobre gastos pessoais e familiares baseada em um artigo lido. Foi muito bom e surgiram várias opiniões e ideias surpreendentes.

Normalmente as aulas são preparadas com base nos livros didáticos e teorias mesmo. Os artigos são mais usados na elaboração de propostas didáticas mais lúdicas como uma caça ao tesouro com códigos ou um estudo de frequência para decifração de mensagens abordando conceitos de estocástica que, embora tenha sido publicado na RENCIMA (como proposta), ainda não foi aplicado por eu estar aguardando a turma chegar na série e conteúdos mais apropriados.

Planejamentos que envolvam leitura e fichamento de artigos. Estudo e discussão de temáticas discutidas. Desenvolvimento de argumentos que possam problematizar o estudo.

Procurei trabalhar com artigos que tinham propostas inovadoras. Essas experiências foram positivas e pude perceber que melhorou a qualidade do ensino e aprendizagem.

Realizei um seminário com uma turma do curso de equações diferenciais e o tema era sobre difusão unidimensional em placas metálicas com diversas condições de contorno. Os alunos tiveram então contato com alguns métodos de solução dessas equações como a transformada de Laplace e a separação de variáveis. Para isso leram revistas científicas e artigos sobre o assunto, o que deixou-os motivados.

Recentemente (2018/1) usei no curso de Geometria I da UFRGS um artigo da REMAT que trata da construção dos polígonos de Dürer.

Se basa en la lectura individual del artículo, formulación de preguntas en clases y comentarios del profesor y estudiantes.

Sempre utilizo artigos em minhas aulas de estágio e práticas de ensino. Discutimos e analisamos os artigos, pois os estudantes precisam escrever artigos nos componentes curriculares dos últimos 4 semestres do curso de licenciatura em Matemática. 
Sim, a leitura panorâmica foi feita para uso do referencial teórico.

Sim, usando um artigo do Grupo de estudos GEPEMat - Grupo de Estudos e Pesquisas em Educação Matemática, que compõe também um dos núcleos do projeto interinstitucional "Educação Matemática nos Anos Iniciais do Ensino Fundamental, preparei um plano de aula para a discipina IEM I.

Usei o artigo como motivador e exemplo de aplicação de atividades matemáticas para ser discutido em sala de aula.

Utilizo os textos da revista para minhas aulas teóricas sobre Educação matemática, assim como utilizo os textos de cunho didático-metodológico para abordagem de algum conteúdo específico.

Fonte: Dados da pesquisa (2018)

Por meio de alguns relatos, percebese que a leitura de artigos por parte dos estudantes de Licenciatura em Matemática tem se motivado pelas oportunidades de produzir e publicar artigos. Fica evidente que essa leitura é fundamental, tanto para promover a familiaridade do estudante com a estrutura de um artigo, como também para agregar aporte teórico à sua formação e, oportunamente, à produção que dela resultará. Aquino (2010) afirma que a leitura aperfeiçoa a fala e a escrita de um modo geral.

Além disso, percebe-se que publicações de relatos de experiência proporcionam importantes trocas entre docentes, como o uso de material concreto e jogos pedagógicos nas aulas de Matemática, suas aplicações e resultados que foram ou podem ser obtidos no que tange ao aprendizado dos alunos envolvidos.

Assim, percebe-se o aproveitamento dos artigos científicos na elaboração de aulas, pois trazem um enriquecimento aos conteúdos dos livros didáticos, ao mesmo tempo que oportunizam debates interessantes em sala de aula. O hábito da leitura de artigos científicos possibilita o pensamento, a inovação e a exploração de novos recursos pedagógicos.

A última seção do formulário teve foco na REMAT. Os questionamentos foram os seguintes: "Você já conhece a REMAT: Revista Eletrônica da Matemática? Em caso afirmativo, como a conheceu?", "Se você já é leitor da
REMAT, tem alguma sugestão para a melhoria de nossos processos?". Dos pesquisados, $70 \%$ já conheciam a REMAT. Pelas respostas, observou-se que a disseminação da REMAT tem se dado, principalmente, por e-mails de divulgação, indicação de amigos e por busca via internet. Nas respostas dos entrevistados também puderam ser tiradas várias ideias para aprimoramento da REMAT, como por exemplo indexação em outras bases de dados, publicação bimestral, aplicativo para selecionar os artigos preferidos, inclusão do DOI, inclusão de datas de possível publicação das edições, interagir com os leitores por meio do lançamento de problemas e discussões divulgando as soluções mais interessantes, manter um corpo editorial competente, mantendo uma análise detalhada para seleção das publicações, entre outras.

Como 30\% dos entrevistados ainda não conheciam a REMAT, surgiu a ideia de trazer este conhecimento científico, em busca da inovação, a um grupo de professores de Matemática que está afastado da academia há muito tempo. Neste sentido, foram realizadas entrevistas com três professores de Matemática da Rede Estadual de Ensino de Caxias do Sul. As perguntas realizadas foram as seguintes: Qual seu grau de formação? Em que nível de ensino você atua como docente? Você já elaborou uma aula de Matemática tomando por base a leitura de algum artigo científico? Na Tabela 4 apresenta-se o perfil dos entrevistados. 
REMAT: análise do perfil de seus usuários por meio da ferramenta Google Analytics e difusão do conhecimento científico entre professores e estudantes de matemática

Tabela 4 - Perfil dos professores de Matemática entrevistados da Rede Estadual de Ensino de Caxias do Sul/RS.

\begin{tabular}{|c|l|l|}
\hline Entrevistado & \multicolumn{1}{|c|}{ Formação } & \multicolumn{1}{c|}{ Perfil profissional } \\
\hline 1 & $\begin{array}{l}\text { Licenciatura em Matemática e } \\
\text { Pós-Graduação. }\end{array}$ & $\begin{array}{l}\text { Professora de Matemática concursada. Regente dos } \\
6^{\circ} \text { e } 7^{\circ} \text { anos do Ensino Fundamental, com } 8 \text { anos de } \\
\text { atuação. Já utilizou artigos científicos em suas práti- } \\
\text { cas pedagógicas. }\end{array}$ \\
\hline 2 & Licenciatura em Matemática. & $\begin{array}{l}\text { Professora de Matemática concursada para atuação } \\
\text { no Ensino Fundamental. Atuante há } 25 \text { anos em } 6^{\circ}, \\
7^{\circ} \text { e } 8^{\circ} \text { anos. Não teve incentivo para a utilização de } \\
\text { artigos científicos em sua Graduação. Afirmou não } \\
\text { conhecer nem a estrutura de um artigo científico. }\end{array}$ \\
\hline 3 & $\begin{array}{l}\text { Engenharia Civil e cursando } \\
\text { Licenciatura em Matemática. }\end{array}$ & $\begin{array}{l}\text { Professora do } 9^{\circ} \text { ano do Ensino Fundamental e do } \\
1^{\circ} \text { e } 3^{\circ} \text { anos do Ensino Médio. Diz já ter utilizado } \\
\text { artigos científicos em aulas da graduação. }\end{array}$ \\
\hline
\end{tabular}

Fonte: Dados da pesquisa (2018)

Pelas entrevistas realizadas, percebeuse uma barreira para a utilização de artigos científicos. Os três entrevistados representam o que geralmente acaba acontecendo entre os profissionais da área. Para o entrevistado 1, a utilização de artigos científicos aparece como uma prática, o que já ocorre par o entrevistado 2 que afirma se quer saber o que seja um artigo científico. Talvez este fato se deva ao entrevistado ter se formado há muito tempo. No relato do entrevistado 3 percebe-se que a utilização de artigos científicos poderia ocorrer de maneira mais significativa, visto que utilizou em sua graduação, porém não utiliza em suas aulas.

Como uma forma de fomentar a leitura, para os entrevistados 2 e 3 foram enviados artigos da REMAT abordando conteúdos que esses professores costumam trabalhar com suas turmas, como uma forma de auxiliá-los a ver novas formas de trabalhar seus conteúdos.

\section{ALCANCE DA REMAT}

De acordo com os relatórios gerados pelo Sistema Eletrônico de Editoração de Revistas (SEER) utilizado pela REMAT, foram contabilizados 19.492 acessos aos resumos e 32.530 acessos aos arquivos PDF/A de 2015 a 2018, conforme mostra a Tabela 5.

Tabela 5 - Número de acessos aos resumos (R) e arquivos PDF/A (PDF/A) de 2015 a 2018

\begin{tabular}{|c|c|c|c|c|c|c|c|c|}
\hline \multirow{2}{*}{ Edições } & \multicolumn{2}{|c|}{$\mathbf{2 0 1 5 / 2 0 1 6}$} & \multicolumn{2}{|c|}{2017} & \multicolumn{2}{c|}{2018} & \multicolumn{2}{c|}{ Total de acessos } \\
\cline { 2 - 9 } & $\mathrm{R}$ & $\begin{array}{c}\text { PD- } \\
\text { F/A }\end{array}$ & $\mathrm{R}$ & $\begin{array}{c}\text { PD- } \\
\text { F/A }\end{array}$ & $\mathrm{R}$ & $\begin{array}{c}\text { PD- } \\
\text { F/A }\end{array}$ & $\mathrm{R}$ & $\begin{array}{l}\text { PD- } \\
\text { F/A }\end{array}$ \\
\hline v. 1, n. 1, 2015 & 94 & 38 & 395 & 493 & 620 & 331 & 1109 & 862 \\
\hline v. 1, n. 2, 2015 & 215 & 284 & 1142 & 1158 & 1876 & 1724 & 3233 & 3166 \\
\hline v. 2, n. 1, 2016 & 712 & 761 & 856 & 2476 & 1591 & 8420 & 3159 & 11657 \\
\hline v. 2, n. 2, 2016 & 516 & 468 & 1604 & 2962 & 1963 & 4641 & 4083 & 8071 \\
\hline
\end{tabular}




\begin{tabular}{|c|c|c|c|c|c|c|c|c|}
\hline v. 3, n. 1,2017 & - & - & 1625 & 1505 & 1485 & 2200 & 3110 & 3705 \\
\hline v. 3, n. 2, 2017 & - & - & 191 & 116 & 2017 & 3686 & 2208 & 3802 \\
\hline v. 4, n. 1, 2018 & - & - & - & - & 2491 & 1236 & 2491 & 1236 \\
\hline v. 4, n. 2, 2018 & - & - & - & - & 99 & 31 & 99 & 31 \\
\hline Total & 1537 & 1551 & 5813 & 8710 & 12142 & 22269 & $\mathbf{1 9 4 9 2}$ & $\mathbf{3 2 5 3 0}$ \\
\hline
\end{tabular}

Fonte: REMAT (2019)

Os dados mostram que, a cada edição, o número de acessos vêm apresentando considerável crescimento, apontando um aumento na busca pelos manuscritos publicados no periódico, o que certamente é um indicativo da qualidade das publicações e da pertinência dos temas abordados. Agora com a adesão à ferramenta de análise Google Analytics espera-se poder mapear o perfil dos leitores, bem como suas necessidades e preferências para entregar ao público-alvo cada vez mais qualidade de conteúdo e facilidade de acesso.

$\mathrm{Na}$ Tabela 6 apresenta-se os dez artigos mais acessados (arquivo PDF/A) bem como a indicação das edições da revista em que foram publicados.

Tabela 6 - Artigos mais acessados (contagem realizada no período de 2015 e 2018)

\begin{tabular}{|l|c|c|}
\hline \multicolumn{1}{|c|}{ Artigo } & Edição & Acessos \\
\hline A Matemática e o lúdico: ensinando frações através de jogos. & v. 2, n. 1 (2016) & 5168 \\
\hline $\begin{array}{l}\text { Cálculo de tarifas e tributos incidentes sobre a conta de energia } \\
\text { elétrica: uma abordagem interdisciplinar no Ensino Médio. }\end{array}$ & v. 2, n. 2 (2016) & 2539 \\
\hline $\begin{array}{l}\text { A utilização do Jogo da ASMD como recurso didático para o } \\
\text { ensino das quatro operações. }\end{array}$ & v. 3, n. 2 (2017) & 1542 \\
\hline $\begin{array}{l}\text { Uma sequência didática para compreender a potenciação e a } \\
\text { radiciação de números complexos. }\end{array}$ & v. 2, n. 1 (2016) & 1183 \\
\hline $\begin{array}{l}\text { Consumo de energia elétrica: uma atividade interdisciplinar na } \\
\text { Educação de Jovens e Adultos. }\end{array}$ & v. 2, n. 1 (2016) & 1136 \\
\hline $\begin{array}{l}\text { Os PCN e o bloco Tratamento da Informação: algumas } \\
\text { possibilidades teórico-metodológicas para a sala de aula da } \\
\text { Educação Básica. }\end{array}$ & v. 2, n. 2 (2016) & 1000 \\
\hline
\end{tabular}

Fonte: REMAT (2019)

\section{CONSIDERAÇÕES FINAIS}

Apesar do curto tempo de existência da revista, a equipe editorial da REMAT vem se dedicando a aumentar a qualidade do conteúdo e investir em ferramentas para facilitar o acesso e aumentar o alcance de suas publicações. Nessa abordagem, a REMAT aderiu ao Google
Analytics, um software de análise de acessos que disponibiliza dados como número de usuários em interação, tempo de acesso por usuário, número de páginas visualizadas, tipo de dispositivo com o qual o usuário acessa o site, localização geográfica dos acessos e forma como o usuário chegou ao site da revista, entre várias outras. Com seu uso, pretende-se coletar 
informações sobre o perfil dos atuais leitores, identificar algumas das suas necessidades e preferências, e aumentar a visibilidade do periódico, cativando novos leitores.

Uma pesquisa entre professores de Matemática e alunos da Licenciatura em Matemática mostrou que $50 \%$ dos entrevistados já fizeram uso de artigos acadêmicos para planejar suas aulas, evidenciando que a troca de conhecimento por esse meio pode enriquecer não somente a atuação docente em sala de aula, mas a formação de futuros professores. Assim, é importante todo esforço no sentido de divulgação do conhecimento científico e de resultados de pesquisas disponíveis em periódicos, para que cada vez mais pessoas, não só pesquisadores e estudantes, tenham

\section{Agradecimentos}

Os autores agradecem o apoio financeiro concedido pela Pró-reitoria de Pesquisa, Pós-graduação e Inovação interesse por esse tipo de conteúdo e que, uma vez interessados, tenham facilidade de acessálo.

Por fim, a análise do crescimento do número de acessos aos manuscritos da REMAT desde sua criação até então, indicam que as melhorias implementadas estão resultando em maior visibilidade e procura da revista, melhor qualidade de conteúdo publicado e maior acessibilidade.

Esses dados certamente encorajam a continuar o trabalho já iniciado e a investir em ferramentas que possibilitem melhor conhecer e atender o público-alvo, suas necessidades e preferências, visando promover avanços no alcance da revista e fomentar a busca pelo conhecimento científico.

(PROPPI) do IFRS, por meio dos Editais 77/2017/PROPPI - Fomento Interno e 10/2018/PROPPI - Apoio à Edição de Periódicos Científicos do IFRS.

\title{
REMAT: ANALYSIS OF THE PROFILE OF ITS USERS THROUGH THE GOOGLE ANALYTICS TOOL AND DISSEMINATION OF SCIENTIFIC KNOWLEDGE BETWEEN TEACHERS AND STUDENTS OF MATHEMATICS
}

\begin{abstract}
REMAT: Revista Eletrônica da Matemática (e-ISSN 2447-2689) comes constituting as a scientific periodic since 2015, having as mission to share educatives practices and research results that relate with the Math. Looking for the journal improvement, evolutions occur in its processes and fluxes, and issues as digital accessibility were addressed, as well it was invested in the journal divulgation by means of e-mail, institutional website and social networks. To encourage the search for scientific knowledge and to characterize REMAT readers, the periodic joined to Google Analytics, an online software for accesses analysis which is available for free by Google. The diversity and nature of collected data, although still very recent, present potential not just for mapping readers profile, but also their necessities and preferences, as well as to follow up the changes of this profile with the evolution of the magazine. Collecting and analysing these information will allow to offer to the target public even more quality content and access facilities. In addition, a research by electronic was carried out and sought to verify if teachers of Mathematics in different levels of teaching and academics of the course of Mathematics use scientific articles to enrich the classes planning. As a main result it was obtained that $50 \%$ of the interviewees already applied knowledge obtained from the reading of scientific articles in the planning of Mathematics classes.
\end{abstract}

\section{Keywords}

User Profile. Google Analytics. Scientific articles. Promotion of Scientific Knowledge.

Artigo recebido em 04/01/2019 e aceito para publicação em 10/02/2019 


\section{REFERÊNCIAS}

ANDREIS, G. S. L.; BOFF, D. S.; MILHOMENS, D. M.; FUCHS, H. L.; ARCARO, K.; SILVA, M. J.; SILVA, R. S. Da inspiração ao projeto REMAT: uma caminhada colaborativa e cooperativa em prol do diálogo científico. In: WORKSHOP DE EDITORAÇÃO CIENTÍFICA, 9., 2016, São Paulo. Anais... São Paulo: Associação Brasileira de Editores Científicos, 2016. p. 24-29. http://dx.doi. org/10.21452/wec.IXwec.2016.0005

ANDREIS, G. S. L.; SILVA, L. H. R.; SILVA, R. S.; ARCARO, K.; FUCHS, H. L.; MILHOMENS, D. M. Reflexões sobre questões contemporâneas emergentes: acessibilidade digital na REMAT - Revista Eletrônica da Matemática. In: ABEC MEETING, 1., 2017, Curitiba. Anais... Curitiba: Associação Brasileira de Editores Científicos, 2017. p. 6-13. http://dx.doi.org/10.21452/ abecmeeting.2017.002.

AQUINO, I. S. Como ler artigos científicos: da graduação ao doutorado. 2. ed. São Paulo: Saraiva, 2010.

PACKER, A. L; MENEGHINI, R. Visibilidade da produção científica. In: POBLACION, D. A.; WITTER, G. P.; SILVA, J. F. M. (Orgs.). Comunicação \& Produção Científica: contexto, indicadores e avaliação. São Paulo: Angellara, 2006.

SILVA, L. H. R.; ANDREIS, G. S. L.; FUCHS, H. L.; ARCARO, K.; SILVA, R. S. Ações desenvolvidas na REMAT: Revista Eletrônica da Matemática com vistas à acessibilidade digital. Ciência da Informação em Revista, Maceió, v. 5 , n. especial, p. 77-85, fev. 2018a. http://dx.doi. org $/ 10.21452 / 23580763.2018 .5$ ne. $77-85$

SILVA, R. E.; VISSIRINI, C. C.; ANDREIS, G. S. L.; ARCARO, K.; SILVA, R. S. Implantação do google analytics na remat e análise do perfil dos usuários . In: ABEC MEETING, 2, 2018, São Paulo. Anais... São Paulo: Associação Brasileira de Editores Científicos, 2018b. p. 1-9. http://dx.doi. org/10.21452/abecmeeting.2018.164

*Versão revista e ampliada do Trabalho "REMAT: análise do perfil de seus usuários por meio da ferramenta Google Analytics e difusão do conhecimento científico entre professores e estudantes de matemática" apresentado no evento ABEC MEETING, 11-14, setembro, São Paulo, SP, 2018. 